\title{
A produção de jogos sérios interdisciplinares na universidade: novos desafios e possibilidades para o ensino da linguagem
}

\author{
Susana Cristina dos Reis ${ }^{1}$ \\ Universidade Federal de Santa Maria \\ suzireis@nte.ufsm.br \\ Adilson Fernandes Gomes ${ }^{2}$ \\ Universidade Federal de Santa Maria \\ adilson.fernandesgomes@gmail.com
}

\section{Resumo}

O ensino da linguagem na contemporaneidade tem sido amplamente desafiado pelo uso de tecnologias digitais na prática docente, principalmente pelas redes sociais e pelos jogos digitais, conforme apontam estudos recentes na área de Linguística Aplicada e Educação. Esses recursos dão acesso às principais atividades sociais realizadas na internet, seja para entretenimento seja para a produção de conhecimento. Assim, envolver alunos em formação inicial em projetos de pesquisa interdisciplinar, no processo de investigação e desenvolvimento de jogos online para o ensino de línguas é urgente, haja vista a necessidade de compreendermos os benefícios dessa prática e como tais recursos podem ser explorados a favor da aprendizagem em sala de aula. Neste trabalho buscamos estabelecer associações entre teoria e prática ao envolver os participantes no design de jogos educacionais, além de vivenciarmos os benefícios dessa associação na formação acadêmica dos integrantes do projeto. Resultados apontam que o desenvolvimento de um projeto dessa natureza promove tanto o letramento digital dos alunos participantes quanto os qualificam como desenvolvedores de conteúdos digitais, técnica ou pedagogicamente para o uso de jogos em sala de aula.

Palavras-chave: Jogos sérios. Ensino de língua inglesa. Desenvolvimento.

${ }^{1}$ Professora Adjunto 3 do Departamento de Letras Estrangeiras Modernas e do Programa de Pós-Graduação em Tecnologias Educacionais em Rede, Líder do GrPesq. Núcleo de Pesquisa, Ensino e Aprendizagem de Línguas a Distância (NuPEAD) - UFSM.

${ }^{2}$ Mestrando do Programa de Pós-Graduação em Tecnologias Educacionais em Rede - UFSM. 
A produção de jogos sérios interdisciplinares na universidade...

\section{Abstract}

The teaching of language in the contemporary world has been widely challenged by the use of digital technologies in the teaching practice, mainly by social networks and digital games, according to recent studies in the field of Applied Linguistics and Education. These resources provide access to main social activities carried out on the Internet, either for entertainment or for the production of knowledge. Thus, to involve undergraduate students in an interdisciplinary research project in the process of investigating and developing digital games for teaching languages is urgent, due to the necessity of understanding the benefits of this practice and how there resources may be explored in favor of learning languages within the classroom. In this paper, we aims at establishing connections between theory and practice by developing educational games. Moreover, we experience the benefits of these connections in initial teacher education. Results show that the development of such project promotes both digital literacy of its members by qualifying them as developers of digital content and pedagogically by using digital games in the classroom.

Keywords: Serious games. English teaching. Development.

\section{Introdução}

A cultura sobre o ato de jogar online no contexto educacional tem sido ampliada ao longo dos anos com relação à prática de jogar. No passado, essa atividade era discriminada e configurava-se, na opinião de alguns, como uma grande perda de tempo ou como um estimulador para a formação de crianças agressivas e violentas (JOHNSON, 2005, p. 15). Atualmente, essas percepções têm sido alteradas, inclusive alguns estudos mostram que jogos de computadores surgem como recursos eficazes para satisfazer as "genuinas necessidades humanas que o mundo real tem falhado em atender" (MCGONIGAL, 2012, p. 14, grifo da autora).

De acordo com McGonigal (2012, p. 14), jogos digitais oferecem recompensas aos seus usuários que a realidade não proporciona, pois os ensinam, inspiram, envolvem e unem de uma maneira que a sociedade muitas vezes não consegue. Para alguns pesquisadores e produtores de jogos online, a realidade contemporânea está esgotada, portanto é preciso começar a desenvolver jogos para consertá-la (MCGONIGAL, 2012, p. 17). Embora essa afirmação seja impactante, jogos digitais têm se mostrado recursos potenciais para aprimorar o desenvolvimento de habilidades e competências (GEE, 2005, p. 34) tão necessárias para os alunos do século 
XXI. Então, por que não explorá-los também em aulas de Línguas Estrangeiras (LE)?

Pesquisa recente, realizada com base na análise de artigos publicados na área de Linguística Aplicada (LA) no Brasil, sugere que os estudos sobre o desenvolvimento e o uso de jogos para o ensino de línguas é um tema pouco debatido nessa área, haja vista que foram encontrados somente 14 artigos em periódicos nacionais de Linguística e Educação, com Qualis/Capes A1, A2, B1e B2 no período de 2009 a 2013 (REIS; BILIÃO, 2014, p. 14). Por sua vez, no panorama internacional, nessa mesma área do conhecimento, estudos que abordam a temática jogos digitais já demonstram um elevado grau de maturidade sobre esse assunto, conforme se pode observar nas pesquisas produzidas por Gee $(2003 ; 2005)$, Prensky (2001), Van Eck (2006) e, mais recentemente, nos estudos de Thorne, Fischer e Lu (2012), Peterson (2012; 2012a), Sylvén e Sundqvist (2012), Zheng, Newgarden e Young (2012), entre outros.

Nesse sentido, as publicações estrangeiras sobre jogos, em outras áreas disciplinares, têm como ponto em comum o fato de não apenas analisarem jogos educacionais ou investigarem recursos e princípios de aprendizagem, mas também valorizarem práticas e competências necessárias para o ensino por meio de jogos online (SQUIRE et al., 2005; ZYDA, 2005; ULICSAK; WRIGHT, 2010; CORNILLIE; THORNE; DESMET, 2012; CORNILLIE; CLAREBOUT; DESMET, 2012; RAMA et al., 2012).

Na mesma direção, os estudos propostos por Gee $(2003 ; 2005)$ sugerem que o uso de jogos na sala de aula pode valorizar a prática de competências e de letramentos necessários para agir na sociedade atual. Para o autor, jogos incorporam bons princípios de aprendizagem, por isso se forem selecionados apropriadamente é possível que os alunos, ao mesmo tempo, aprendam e se divirtam com eles.

Em contrapartida, o estudo de Wittke e Reis (2013, p. 417) indica que nem todo jogo promove a aprendizagem significativa de um conteúdo específico. Isso se evidenciou a partir da análise de jogos do tipo edutainment, nos quais a interação, a produção e a imersão dos alunos são limitadas para possibilitar a simulação ou a prática do uso da linguagem (GEE, 2005; GILLEN; BARTON, 2010). A falta desses elementos em um jogo educacional tende a não favorecer a aprendizagem significativa, uma vez que não contempla em sua plataforma princípios tão essenciais para promover a aprendizagem de línguas. 
A produção de jogos sérios interdisciplinares na universidade...

A partir dessas pesquisas, percebemos que a inserção e o processo de criação de design de jogos educacionais em aulas de LE não são práticas simples de serem efetivadas, visto que precisam ser analisadas, planejadas e vivenciadas pelos participantes envolvidos nessas atividades. Por esse motivo acreditamos que, para minimizar essas limitações, técnicos, designers e professores de línguas necessitam dialogar e trabalhar interdisciplinarmente a fim de fomentar a análise, o desenvolvimento e a construção colaborativa desses jogos, os quais devem contemplar bons princípios de aprendizagem.

Portanto, neste trabalho, buscamos estabelecer relações entre teoria e prática ao descrever o design de um jogo educacional envolvendo alunos em formação inicial dos cursos de Letras, de Ciência da Computação e de Artes Visuais empenhados em um projeto no contexto acadêmico.

\section{Pressupostos teóricos para o desenvolvimento e a aplicação de jogos na educação}

De acordo com estudos prévios sobre Aprendizagem Mediada por Jogos Digitais ${ }^{3}$ (AMJD), aprendemos quando estamos envolvidos em atividades direcionadas que possibilitam nosso engajamento significativo para a produção de conhecimentos diversos (GEE, 2003; 2005). Portanto, ao nos inserirmos em contextos de jogos digitais, simulamos e nos engajamos em práticas que podem potencializar a aprendizagem significativa. Diante disso, investigar como pesquisadores renomados entendem a AMJD implica investigar conceitos e abordagens em discussão tanto na área de CALL quanto na multidisciplinar para aprofundarmos o conhecimento teórico sobre o processo de desenvolvimento e de aplicação de jogos digitais nas práticas pedagógicas.

Para isso, torna-se importante entendermos alguns conceitos que emergem nessas áreas, entre os quais estão a definição de jogos online, jogos educacionais, jogos sérios e princípios de aprendizagem em jogos. Jogos online são definidos por Zyda (2005, p. 25) como uma competição mental, jogada por meio de computadores ou outros dispositivos, que possui regras específicas para proporcionar entretenimento, diversão ou competição. Para Ulicsak e Wright (2010, p. 17), jogos online são

\footnotetext{
${ }^{3}$ Em inglês DGBL (Digital Games Based Learning).
} 
atividades divertidas e envolventes, as quais geralmente são acessadas na internet e podem ser exploradas exclusivamente para o entretenimento.

No contexto desses jogos, os participantes são expostos a uma série de ferramentas, movimentos, ideias e interações geradas em um mundo sintético ou virtual cujos desafios são estruturados por metas específicas, regras bem estruturadas, mecanismos de feedback e recursos necessários para suportá-los (MCGONIGAL, 2012, p. 30). Nesses contextos, Ulicsak e Wright (2010, p. 17) sugerem que é possível desenvolver diferentes tipos de jogos com propósitos educacionais, a saber: simulações, mundos virtuais e jogos sérios.

As simulações são jogos que pretendem treinar seu usuário a fim de que este possa utilizar as competências que desenvolveu não somente no mundo virtual, mas também no mundo real. Os mundos virtuais são contextos tridimensionais nos quais o usuário percorre o cenário proposto motivado por um jogo, avançando para novos ambientes, porém sem necessariamente ter um objetivo específico. Por sua vez, os jogos sérios são definidos como jogos com características de entretenimento, no entanto são projetados para fins sérios, ou seja, proporcionar a capacitação corporativa, a educação, a saúde, as políticas públicas e, ainda, com fins estratégicos de comunicação (ZYDA, 2005, p. 25).

Segundo Perera et al. (2010, p. 256-257), existem inúmeras vantagens para o uso desses recursos na educação, tanto como uma ferramenta de apoio para o ensino presencial quanto como plataforma para o ensino a distância. Entre as vantagens estão a existência de um ambiente rico em gráficos e simulações em 3D que potencializam a demonstração de conceitos mais complexos, permitindo disponibilizar conteúdos multimodais, e facilitar a colaboração entre os alunos, inclusive fisicamente distantes. Além disso, mundos virtuais podem incorporar elementos de jogos em suas atividades, o que não é muito comum acontecer em outras plataformas de ensino e aprendizagem, tais como no Moodle e outros. Contudo, o engajamento dos alunos em mundos como OpenSim ou Wonderland pode ser muito mais amplo, visto que em espaços tridimensionais eles se tornam mais ativos ao assumir a identidade de um avatar ou, ainda, ao vivenciar a simulação.

No caso específico do ensino de LE, mundos virtuais e/ou mundos multiusuários, como Second Life ou OpenSim, têm sido utilizados como ambientes para realização de atividades educacionais, destacando-se como contextos potenciais para promover a simulação de atividades de 
A produção de jogos sérios interdisciplinares na universidade...

aprendizagem. Particularmente, no ensino de línguas esses recursos possibilitam aos alunos a imersão, ocasionando a aprendizagem experiencial (PERERA et al., 2010, p. 258), o gerenciamento do discurso, a participação e a autonomia dos aprendizes (PETERSON, 2012, p. 362), bem como a prática situada de LE, assegurando assim a interação colaborativa na aprendizagem de léxicos e de usos da língua-alvo em situações reais de interação.

Portanto, a utilização de jogos sérios/críticos como suporte para os processos de ensino e aprendizagem tem se expandido em diversos setores da sociedade contemporânea. No entanto, esse uso tem sido encontrado mais recorrentemente em aplicativos para as áreas de medicina, militar, governamental, entre outras.

Tendo em vista entender como jogos online podem ser explorados nos processos de ensino e aprendizagem de línguas, na sequência descrevemos as principais abordagens de uso de jogos no ensino sugeridas na literatura recente.

\subsection{Abordagens para a produção e o uso de jogos nos processos de ensino e aprendizagem}

A literatura sobre AMJD revela ainda que, em geral, os educadores têm adotado três abordagens para integrar jogos no processo de aprendizagem. Para Van Eck (2006, p. 8-12), as principais abordagens são: 1) a elaboração de jogos pelos próprios estudantes; 2) a inclusão de educadores e/ou desenvolvedores técnicos no desenvolvimento de jogos educacionais interdisciplinares; e 3) o uso de jogos comerciais em sala de aula.

Embora o autor apresente essas abordagens, no caso específico do ensino de línguas estas não são suficientes para esclarecer ao professor como explorar esse recurso no ensino, haja vista que nenhuma delas explicita como é possível aplicar jogos na prática de ensino de LE. Ao desafiar os alunos na produção de jogos, com base em um projeto ou como tarefa em sala de aula, os estudantes assumem o papel de designers e de programadores de jogos. Tradicionalmente, essa prática tem sido mais significativa para os estudantes da área de Ciências da Computação, pois os alunos nessa situação desenvolvem habilidades de resolução de problemas enquanto aprendem linguagens de programação (VAN ECK, 2006, p. 15). Nessa abordagem, os alunos produzem conhecimentos variados, que 
incluem conhecimentos técnicos específicos, de design, de orientação em objetos e de programação para implementar o protótipo de um jogo.

Outra abordagem comum para a produção de jogos é a possibilidade de cruzar múltiplas disciplinas em um mesmo projeto, integrando na proposta o desenvolvimento de jogos interdisciplinares. Nesse caso, nem todos os participantes envolvidos no projeto têm as habilidades necessárias para o design de jogos e também não ensinam em áreas que permitem a produção de conteúdos mais interativos para implementar esse tipo de AMJD (VAN ECK, 2006, p. 6).

No caso de desenvolvimento/produção de jogos, na área de Linguística/Línguas Estrangeiras acreditamos que adotar uma abordagem interdisciplinar para a produção de jogos no ensino pode ser uma alternativa tanto para o ensino de línguas quanto para a pesquisa, pois tal abordagem se configura como uma proposta de trabalho interdisciplinar que poderá ser muito rica para engajar os alunos na produção de jogos em sala de aula, haja vista a necessidade urgente de ampliar a visão de futuros professores (alunos em formação inicial) quanto ao uso desses recursos em sala de aula.

Para isso, julgamos importante fomentar nas universidades projetos interdisciplinares que explorem tanto o processo de produção quanto o uso de jogos online no ensino de LE para que, com base nessas experiências, possamos construir conhecimento teórico-pedagógico quanto ao uso de tais recursos em sala de aula de LE, tendo em vista que jogos se mostram como recursos potenciais para promover a motivação e a aprendizagem de línguas.

O uso de jogos comerciais nas aulas de LE constitui uma alternativa mais efetiva para o ensino, visto que encontramos na internet uma variedade de jogos online que podem ser explorados na prática de ensino para potencializar a aprendizagem de línguas. Jogos comerciais são desenvolvidos com o propósito de atender às tendências comerciais. No entanto, mediante uma abordagem pedagógica, são integrados ao contexto educacional formal, contribuindo para os processos de ensino e aprendizagem. Os estudos de Gee $(2003 ; 2005)$ enfatizam a importância de explorar bons jogos de forma pedagógica, uma vez que são desenvolvidos com princípios bem estruturados de jogabilidade e de aprendizagem, tornando-se assim recursos em potencial para o ensino e a aprendizagem na escola. 
A produção de jogos sérios interdisciplinares na universidade...

Dessa maneira, compreender os jogos como um recurso pedagógico favorece ainda a aprendizagem crítica (GEE, 2005), do mesmo modo que se torna um grande desafio tanto para professores quanto para pesquisadores. Para melhor exemplificar essa discussão, Gee (2005, p. 3437) apresenta 16 princípios que podem promover a aprendizagem. Para melhor entendê-los, segue nossa interpretação sobre esse assunto.

\subsection{Princípios de aprendizagem em jogos comerciais}

Para entendermos os benefícios do uso de jogos no contexto acadêmico, na sequência descrevemos os princípios de aprendizagem propostos por Gee (2005), recorrentemente encontrados em jogos online.

No ato de jogar, os jogadores assumem a identidade de seus avatares e passam a vivenciar emoções, situações e práticas de seus personagens. Com isso, esses jogadores comprometem-se com o novo mundo virtual, no qual vivem, aprendem e agem por meio dessa nova identidade (GEE 2005, p. 34). Da mesma forma, no processo de aprendizagem de uma LE, para que o aluno efetivamente aprenda é preciso receber insumo linguístico e estar em um contexto que favoreça sua aprendizagem (BARKHUIZEN, 2004; LITTLEWOOD, 2004). Para tanto, ao se inserir em um contexto simulado imersivo, como acontece em um jogo, a aprendizagem pode acontecer se o sujeito realmente assumir uma identidade, buscando realizar tarefas que o desafiem a alcançar determinados objetivos.

Outro princípio observado em jogos é o da interação, que vem ao encontro do que já afirmava Vygostky (2008, p. 38) sobre aprendizagem, pois é a partir da interação com outros que o sujeito aprende. Dessa forma, ao assumir uma identidade e ao interagir dentro de um ambiente virtual multiusuário, a interação dos participantes é observada a cada tomada de decisão que ele realiza nesse contexto, pois os jogos permitem um encadeamento de ações por meio da busca pela solução de novos problemas ou desafios, exigindo novas ações a cada nova tomada de decisão do participante (GEE, 2005, p. 34).

Todo bom jogo requer também uma boa ordenação dos problemas, ou seja, é preciso ordenar as atividades, buscando a resolução dos problemas em níveis crescentes, de menor grau para o maior grau de dificuldade. Nesse caso, o desafio e a consolidação para a solução de um problema convergem para que o participante adquira um conhecimento. 
Logo em seguida, o jogo torna a desafiá-lo, lançando um problema mais complexo que o primeiro, exigindo do participante novamente a procura por soluções ao utilizar seu conhecimento prévio e a experiência anterior (GEE, 2005, p. 36).

Em um bom jogo, os participantes são produtores ativos de suas ações, tomando as decisões necessárias para atingir suas metas, sendo também responsáveis por exteriorizar a produção de sua aprendizagem (BARKHUIZEN, 2004; LITTLEWOOD, 2004). Assim, os jogadores são encorajados a correr riscos, por isso um bom jogo deve reduzir as consequências das falhas dos jogadores quando erram, oferecendo feedback e possibilitando que retorne ao último estágio salvo no jogo (GEE, 2005, p. $35)$.

Nesse contexto, é o aluno que customiza sua aprendizagem. Ao longo de suas experiências, ele descobre seu estilo e as estratégias que favorecem a aquisição de um dado conhecimento (OXFORD, 1999, p. 110). Em jogos, a customização está relacionada à capacidade de ajuste ao estilo de aprender e de jogar do participante, delimitada nos níveis de dificuldades presentes nas fases, possibilitando ao sujeito a capacidade de agenciar, ou seja, sentir total controle e propriedade sobre o que está fazendo no jogo (GEE, 2005, p. 35-36).

As informações e as ajudas em um bom jogo são fornecidas na hora certa. Para tanto, esse procedimento ocorrerá automaticamente a partir do momento em que se iniciar o jogo, basta ao usuário identificá-las e utilizálas em conformidade com seus propósitos e, ainda, a pedido, isto é, quando o participante necessitar ou desejar ajuda durante o jogo poderá recorrer à informação de outros usuários ou encontrará dicas no próprio jogo (GEE, 2005, p. 36).

Portanto, todo bom jogo deve gerar frustração prazerosa. Nesse caso, é o desafio o responsável por tornar o jogo altamente motivador para os participantes. Diante dessa perspectiva, se os jogadores falharem eles serão instigados a tentar novamente a partir de onde pararam (erraram). Jogos digitais incentivam que se desenvolva o pensamento sistemático. Os participantes devem ter a capacidade de ampliar suas relações estabelecidas no jogo, as quais estão vinculadas ao engajamento nas ações do jogo por meio do contato com outros participantes em jogos multiusuários. $\mathrm{O}$ surgimento de equipes transfuncionais concretiza-se quando os participantes jogam em grupos (múltiplos jogadores). Nessa situação, apesar de o jogo ser em equipe, cada integrante exerce uma função com 
A produção de jogos sérios interdisciplinares na universidade...

habilidades e tarefas diferentes, porém todos têm a mesma meta (missão) em comum (GEE, 2005, p. 36).

De acordo com Gee (2005, p. 36), no mundo globalizado e complexo em que vivemos promover o pensamento sistemático é essencial para todos, pois trabalhar em equipe, incentivar a aprendizagem colaborativa e compartilhar conhecimentos são competências fundamentais a serem aprimoradas pelos alunos da sociedade atual.

Todo o encorajamento do participante exige também o emprego de outro princípio: explore, pense literalmente, repense os objetivos do jogo, fazendo com que o participante reflita sobre as ações que irá executar (decisões), ampliando lateralmente sua rede de interação, pois cada ação acarretará uma futura reação no jogo, que poderá favorecer ou dificultar sua chegada ao objetivo. Assim, ao conhecer e explorar o contexto do jogo, a aprendizagem situada poderá ser desencadeada, pois possibilitará interligar os significados das palavras em termos de ações, imagens e diálogos de modo contextualizado, favorecendo a aprendizagem por meio de sentidos contextualizados e a aprendizagem da linguagem em uso. Em jogos, as palavras não devem ser proferidas isoladamente, fora de um contexto, elas deverão estar relacionadas a uma experiência vivenciada e podem variar mediante novas ações, imagens e diálogos, sempre em torno de um contexto (GEE, 2005, p. 36), situando o aluno na história (narrativa) do jogo e dando-lhe todo o contexto em que se passam as atividades.

Para tanto, é necessário recorrer também às ferramentas inteligentes e aos conhecimentos distribuídos, que existem em jogos e passam a ser compartilhados por meio dos avatares e jogadores. Os participantes precisam assumir as habilidades dos personagens virtuais que atuam individual ou coletivamente (GEE, 2005, p. 36-37), visando a trabalhar em equipe de modo que cada membro contribua com o desenvolvimento de suas habilidades distintas. Nessa situação, o conhecimento básico para jogar passa a ser distribuído entre pessoas reais e seus personagens virtuais inteligentes. Segundo Gee (2005, p. 36-37), ferramentas inteligentes e conhecimentos distribuídos são habilidades essenciais para a produção do conhecimento na modernidade.

$\mathrm{O}$ último princípio é a performance anterior à competência. Nele os participantes podem ter o desempenho de jogar antes mesmo de serem competentes, pois podem ser apoiados pelo design, pelas ferramentas inteligentes do jogo e pela interação com participantes de níveis mais avançados (GEE, 2005, p. 37). Na tentativa de desenvolver um jogo de 
inglês que considere os princípios de aprendizagem presentes em bons jogos, procuramos no projeto em desenvolvimento em nosso grupo de pesquisa implantar ações e procedimentos que caracterizem esses princípios com o intuito de produzir um bom jogo educativo. Na sequência, abordaremos os procedimentos metodológicos adotados neste estudo.

\section{Metodologia do estudo}

$\mathrm{Na}$ revisão da literatura buscamos suportes teóricos que nos possibilitassem a adoção de uma abordagem interdisciplinar no projeto, procurando integrar diferentes disciplinas para o desenvolvimento de jogos educacionais, explorando saberes de diferentes áreas disciplinares, tais como Língua Inglesa, Artes, Educação Ambiental e Tecnologias. Com isso, adotamos como abordagem de pesquisa e desenvolvimento integrar jogos online no processo de aprendizagem tendo por base as abordagens previstas nos estudos sobre aprendizagem mediada por jogos digitais ${ }^{4}$ descritas por Van Eck (2006, p. 8-12), ou seja, buscamos: 1) propor a elaboração de jogos pelos próprios estudantes participantes do projeto; 2) incluir educadores, alunos (Letras, Artes e Tecnologias) no desenvolvimento de jogos educacionais; e 3) implementar na produção do jogo online os princípios de aprendizagem de Gee (2005).

Van Eck (2006, p. 8-12) afirma que diferentes áreas do conhecimento podem trabalhar colaborativamente na elaboração de um jogo. Dessa maneira, alunos e professores envolvem-se nas atividades, possibilitando a interdisciplinaridade. Para ilustrar essa abordagem, buscamos encontrar soluções para a produção e o uso de jogos educativos de LI na sala de aula, bem como investigar novas possibilidades para o ensino da linguagem por meio das ações de um grupo de pesquisa (GrPesq NuPEAD) na Universidade Federal de Santa Maria.

No GrPesq formamos uma equipe de alunos e professores que participam e trabalham colaborativamente no projeto a fim de garantir que todos os aspectos do desenvolvimento do jogo sejam abordados, desde a parte técnica, como programação e design, até a sustentação teórica, para propor uma narrativa e desafios que engajem os participantes no jogo.

\footnotetext{
${ }^{4}$ Digital Games Based Learning.
} 
A produção de jogos sérios interdisciplinares na universidade...

Esta pesquisa é um estudo de caso. Primeiramente realizamos uma pesquisa bibliográfica para fundamentar as ações realizadas no desenvolvimento do jogo. Além disso, utilizamos como instrumentos de coleta de dados questionários de diagnóstico e de avaliação, com perguntas abertas e fechadas, para coletar opiniões dos alunos em formação inicial quanto à sua participação no projeto. Os dados obtidos dessa experiência serão discutidos na próxima seção.

\section{Discussão e implementação dos princípios de aprendizagem na produção do jogo educacional}

Um dos projetos desenvolvidos no nosso grupo de pesquisa buscou investigar o processo de produção de um jogo para o ensino de LI que abordasse o ensino da língua-alvo e a conscientização ambiental dos usuários por meio do jogo online. No contexto do jogo, buscamos implementar o uso da linguagem como uma prática social (FAIRCLOUGH, 2004, p. 225) ao prever a inserção do usuário em diferentes gêneros e contextos que conciliassem textos verbais e não verbais na tentativa de conscientizar o participante do jogo quanto à necessidade de manutenção, preservação e revitalização do meio ambiente previsto no cenário do jogo.

$\mathrm{Na}$ narrativa, buscamos implementar os diversos princípios de aprendizagem que definem as características presentes em um bom jogo (GEE, 2005). Entre os diferentes princípios contemplados nas fases iniciais podemos destacar primeiramente o princípio da identidade, ou seja, no jogo o aluno assume o papel de um agente do governo a fim de desvendar os problemas existentes em uma cidade fictícia por meio da investigação e da aquisição de informações a partir da interação com Non playable characters (NPCs) ${ }^{5}$ e com outros jogadores. Assim, o jogo se inicia com o aluno assumindo a identidade do agente investigativo e imergindo no mundo do jogo, vivenciando experiências para solucionar os desafios propostos.

A principal meta da fase inicial é familiarizar os alunos com as ferramentas e a história do jogo. Desse modo, primeiramente o aluno recebe informações sobre o uso das ferramentas, tais como o inventário, o

\footnotetext{
${ }^{5}$ Non playable characters (NPCs) ou personagens não jogáveis (em português).
} 
chat, os controles de movimento, o mapa, e dicas de como se darão as interações com os personagens não jogáveis ou NPCs. Para iniciar sua atuação no jogo, os alunos customizam seus avatares e sua aprendizagem, podendo escolher entre diversas opções características físicas, roupas e calçados, criando seu personagem da maneira que melhor lhes agradar. Essa possibilidade caracteriza o princípio da customização.

Após as primeiras orientações, o aluno inicia o jogo e se insere em diferentes contextos. Por exemplo, o aluno explora o contexto de entrada de uma praça na qual há um vídeo introdutório que será ativado, contextualizando a história ao jogador (Figura 1) (REIS et al., 2012, p. 56). Após assistir ao vídeo, o aluno interage com um NPC que está na praça, o qual dará instruções para que o jogo se inicie. Em seguida, poderá realizar a leitura multimodal do cenário (praça da cidade), e com base nas dicas (pistas) encontradas (vídeos, NPCs) o aluno passa a vivenciar a história do jogo.

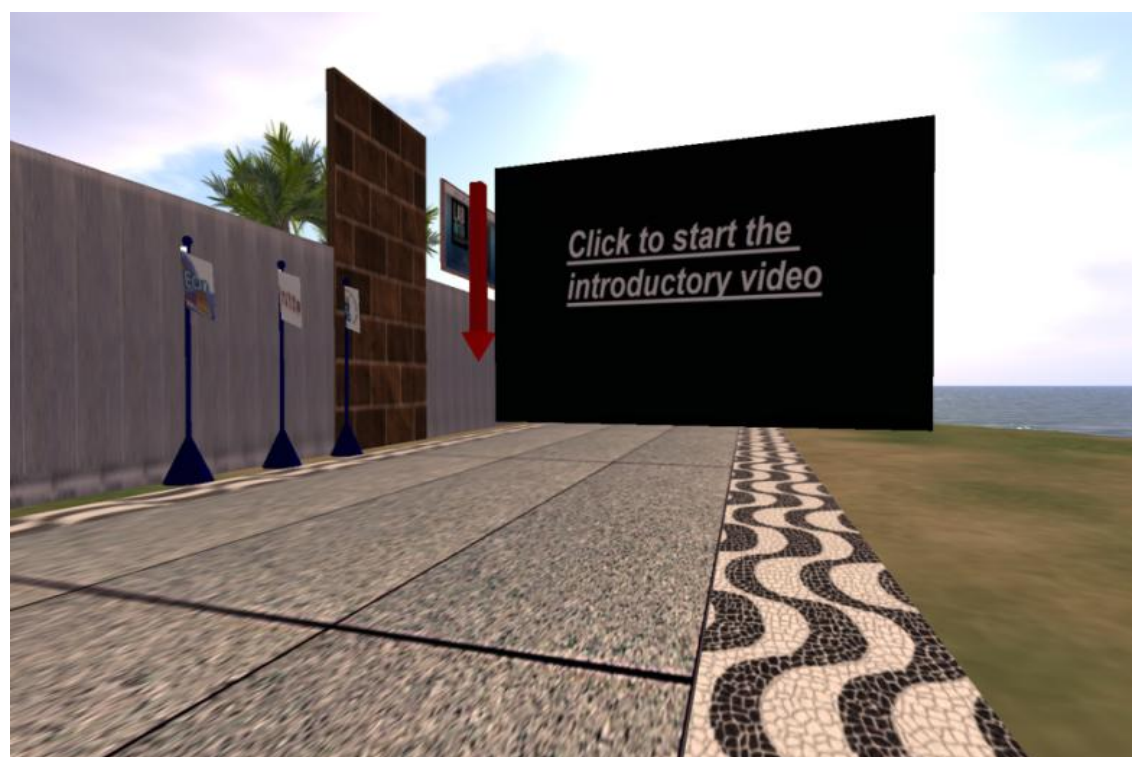

Figura 1. Vídeo introdutório da fase 1 do Jogo I-AI3

Elaborar desafios que engajam o jogador na narrativa não é uma atividade simples de ser implementada. No jogo, por exemplo, o primeiro desafio do agente é identificar o que está causando o alto nível de poluição 
A produção de jogos sérios interdisciplinares na universidade...

na cidade. Para isso, esse agente precisa entrevistar os moradores a fim de obter pistas, dicas e respostas às suas dúvidas, também deverá coletar exemplares dos resíduos poluentes na praça objetivando identificar e investigar os riscos que esses resíduos oferecem à população. Na narrativa, as consequências da poluição geraram modificações na aparência dos personagens, mutações que afetam o corpo e a saúde dos moradores. Ao solucionar esse desafio, o aluno recebe recompensas que favorecerão a realização de outras tarefas no decorrer do jogo, além de obter o direito de seguir para uma nova fase.

Ao desenvolver uma interface multijogador em um jogo online, as interações acontecem em diferentes momentos das fases, pois os jogadores poderão conversar entre si via chat, trocar informações, realizar atividades nas quais terão de trabalhar individualmente ou em equipe, pois, nos grupos, os integrantes devem interagir com o propósito de superar os desafios existentes e atingir as metas de cada fase. Essas possibilidades oportunizam aos participantes a criação de redes de cooperação e colaboração no ato de jogar, além de caracterizarem os princípios da interação e das equipes transfuncionais.

$\mathrm{Na}$ primeira versão do projeto I-AI3 (REIS; SOUZA; GOMES, 2012; REIS et al., 2012), a plataforma OpenSim foi utilizada como contexto de imersão, pois oferece possibilidade de interação entre os alunos e é voltada para a criação de ambientes interativos. Com isso, esses alunos se inserem no contexto do jogo e podem socializar com os outros a fim de conseguir informações para a realização das tarefas.

Durante toda e qualquer atividade no jogo, o aluno recebe instantaneamente informações, dicas e pistas de como proceder por intermédio de pop-ups. Essa ajuda é ofertada a partir do momento em que se inicia esse jogo. Além disso, o aluno pode solicitar ajuda ao tutor online que estiver aplicando as atividades sempre que achar necessário. Nessas duas situações ficam caracterizados os princípios de ajuda na hora certa e a pedido.

Implementar situações-problema que levem os alunos à interação, por meio de desafios contextualizados pela narrativa do jogo, permitem criar uma narrativa com um enredo linear e ordenado, com desafios do nível mais fácil ao mais complexo, o que gera confiança e estímulo ao aluno envolvido no jogo. Nesse sentido, no jogo a narrativa insere o participante em um contexto com início, meio e fim, e tal linearidade e ordenação identificam os princípios da boa ordenação dos problemas e do 
desafio e consolidação, pois o aluno interage com a história conforme for completando as atividades.

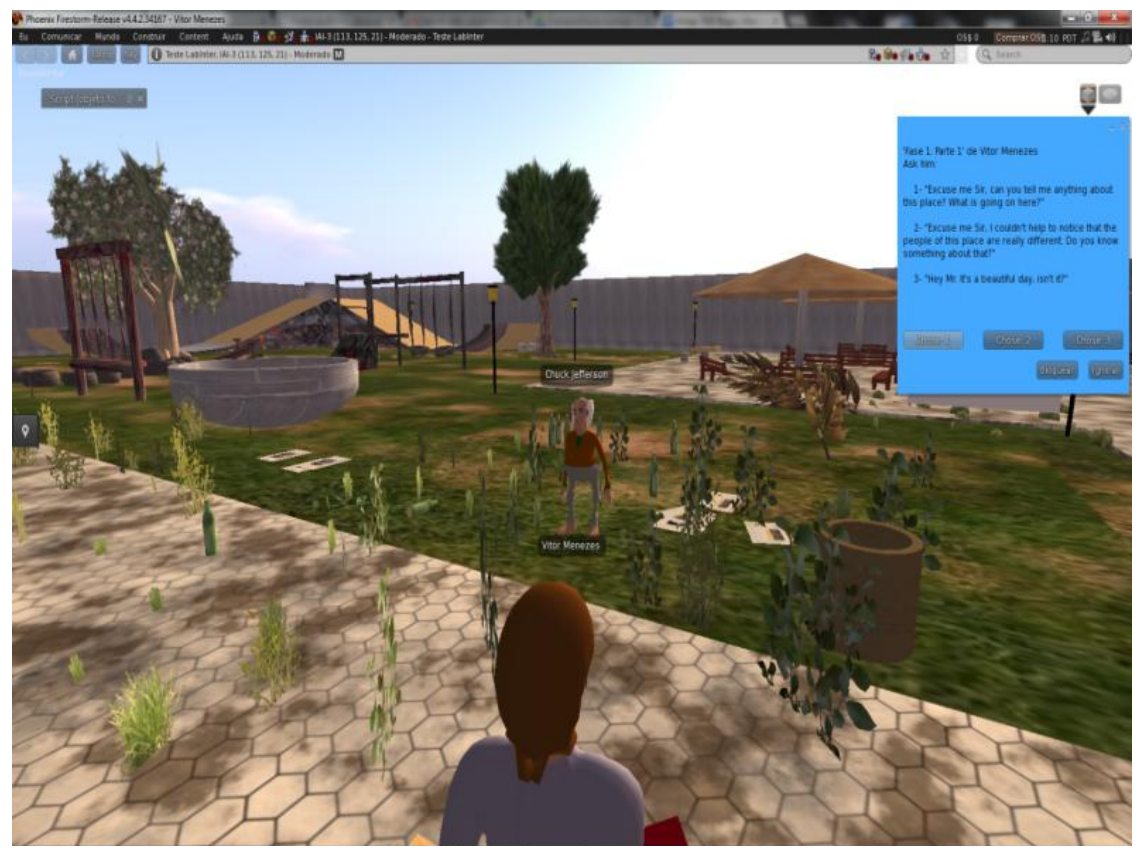

Figura 2. Diálogos na fase 1

Simular situações que possibilitem ao aluno interagir (Figura 2) com diversos NPCs, instigando-os à descoberta, é uma maneira de fazer com que os jogadores busquem solucionar os problemas propostos para, posteriormente, receber recompensas pelas atividades realizadas. No Jogo I-AI3 (REIS; SOUZA; GOMES, 2012; REIS et al., 2012), o aluno, ao mesmo tempo em que joga, aprende a realizar a coleta seletiva de lixo, recebe informação sobre os resíduos poluentes que necessitam passar por coleta e análise para que o problema possa ser descoberto. Assim, os jogadores circulam pelo local coletando amostras de resíduos poluentes, colocando-os em seus inventários e, posteriormente, levando-os para análise em uma máquina simuladora de danos causados por tais resíduos. A máquina simuladora (Figura 3) é disponibilizada em um determinado ponto da cidade e irá ajudar os alunos/agentes na análise e na seleção das amostras de resíduos para uma posterior reciclagem. Esse será o ponto de 
A produção de jogos sérios interdisciplinares na universidade...

encontro da equipe de agentes e ambientalistas para discussão dos problemas identificados até o momento.

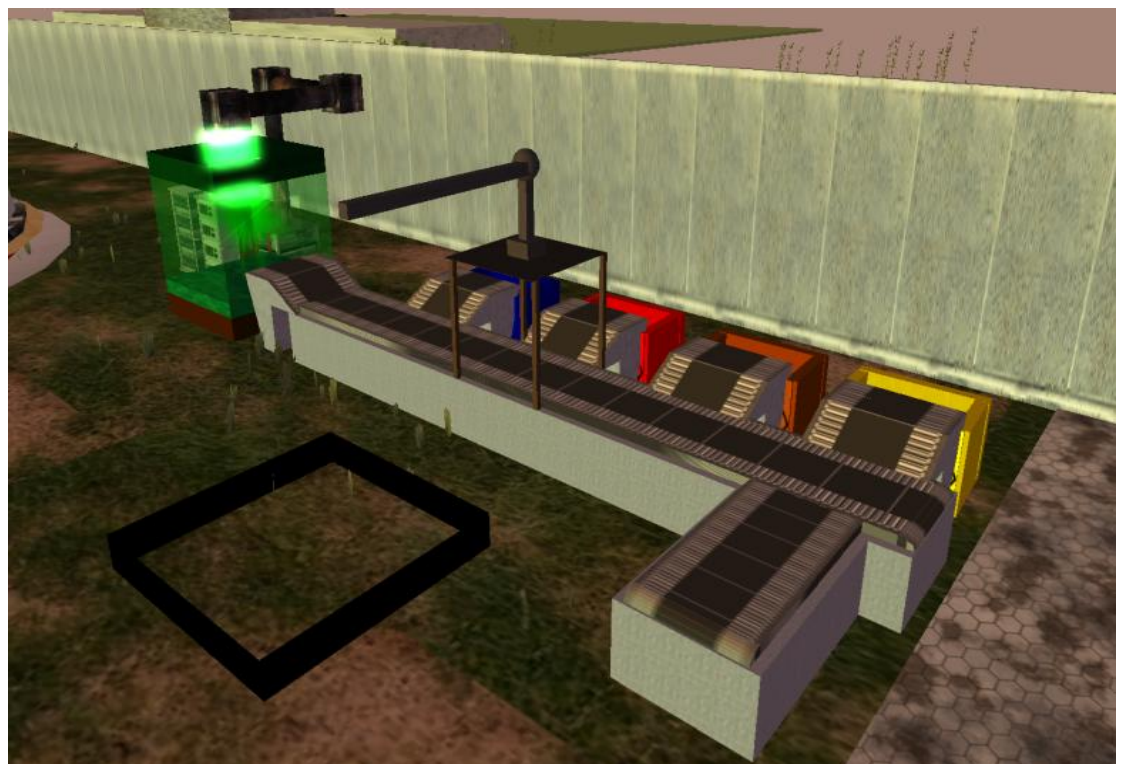

Figura 3. Máquina de análise do lixo

Jogos multijogadores permitem que os alunos realizem atividades individualmente ou em grupo para atingir as metas. Cada jogador possuirá um número mínimo e um número máximo de atividades a serem realizadas. Caso um aluno não consiga atingir sua meta, seus colegas poderão interagir, ajudando e, até mesmo, indicando a localização dos objetos, promovendo desse modo ações colaborativas e fornecendo ajuda e suporte linguístico ao colega (se necessário) para buscar a solução dos problemas propostos colaborativamente.

Multiletramentos e habilidades linguísticas são competências a serem implementadas por meio de um jogo. Ao ler, interpretar e atuar no cenário virtual o aluno se insere em diferentes situações comunicativas que possibilitam a ele usar a linguagem para comunicar-se. Nesse contexto, esse aluno interage pela escrita, no chat e também na produção de gêneros requeridos nos desafios.

O aluno poderá ainda fazer suas próprias escolhas ao interagir no jogo - tanto dar sequência às falas e às interações com os NPCs quanto 
realizar a coleta de lixo, pois a tomada de decisão acarretará em uma ação, ou seja, ele corre o risco de a decisão não ser a correta, mas apesar do seu erro poderá retomar o jogo e dar sequência a ele do ponto onde parou (errou), completando o desafio no jogo. Isso remete aos princípios do risco, da frustração prazerosa e do pensamento sistemático. Nesse sentido, toda ação executada pelo aluno no I-AI3 em busca de soluções para um desafio estimulará as interconexões de saberes tanto do conhecimento internalizado desse aluno quanto dos oportunizados pelo próprio jogo, proveniente da associação de dicas e informações (pop-ups) ou da interação entre os integrantes. A partir do momento em que essas interconexões de saberes e rede de relacionamentos são ativadas pelos alunos emerge um novo princípio - explore, pense literalmente, repense os objetivos do jogo.

$\mathrm{O}$ ambiente ficcional do Jogo I-AI3 exige que o aluno realize associações multimodais (verbais e não verbais) para dar significados e entendimentos das ações que deverão ser executadas no cumprimento de seus objetivos. Com isso, conectar elementos não verbais com as expressões e as dicas verbais em língua inglesa, recebidas na tela do computador, poderá levar à internalização do conhecimento pelo aluno. A imersão nesse contexto ficcional, com posterior empregabilidade dos conhecimentos adquiridos no mundo real, remete-nos ao princípio dos sentidos contextualizados.

Como profissionais envolvidos no ensino mediado por tecnologias, entendemos que os alunos já trazem determinadas experiências com jogos online para o contexto escolar, as quais irão influenciar em sua performance. Em contrapartida, associar, selecionar e empregar recursos no design do jogo que ofertem apoio para um maior desempenho dos alunos, por meio da interação e da cooperação, é uma atividade complexa que pode favorecer o princípio da performance anterior à competência.

No I-AI3, a narrativa ficcional propõe que os alunos vivenciem as atividades práticas de agentes investigativos e cidadãos preocupados com sua localidade e, ao mesmo tempo, em seu contexto real escolar, que os alunos estejam aprendendo uma língua estrangeira, no caso, a língua inglesa, e colocando em prática as mesmas atitudes tomadas no jogo com relação ao cuidado com o meio ambiente. Para realizar essas ações, os alunos adquirem as habilidades dos personagens virtuais para atingir suas metas no jogo e evoluem como aprendizes de uma língua estrangeira. Dessa forma, fica evidenciado o princípio das ferramentas inteligentes e 
A produção de jogos sérios interdisciplinares na universidade...

conhecimentos distribuídos, que passa a ser compartilhado tanto no mundo real quanto no virtual.

A experiência de elaboração de desafios linguísticos em jogos interdisciplinares é uma atividade desafiadora para a equipe de desenvolvimento. As atividades que preveem explorar a produção de gêneros discursivos no jogo se realizam com base nos eventos e nas situações comunicativas previstas na narrativa do jogo. Portanto, se a narrativa proposta não estiver com um enredo bem definido, isso dificultará a previsão de tais práticas. No caso do I-AI3, os gêneros discursivos previstos são a entrevista, a produção de uma lista de itens, os diálogos, os relatórios produzidos pelos agentes, a produção de um $e$-mail, a síntese de informações e o bate-papo informal. Nessas situações comunicativas os jogadores são desafiados a aprender a linguagem por meio do uso e da interação de modo contextualizado.

Neste artigo descrevemos os pressupostos teóricos que têm norteado a construção de jogos educacionais e percebemos que novos desafios e possibilidades para o ensino da linguagem têm emergido ao longo do desenvolvimento do jogo. Também consideramos a necessidade de integrar essa tecnologia à sala de aula. Na sequência, discutimos a experiência de desenvolvimento vivenciada pelos alunos da graduação envolvidos no projeto, os quais diariamente executam as tarefas. Portanto, julgamos necessário aos alunos em formação inicial não apenas conhecer os pressupostos que suportam jogos educativos e/ou comerciais, como também explorá-los como recursos didáticos, na medida em que tais contextos proporcionam ao aluno a experimentação imersiva com base na simulação e na prática situada da linguagem.

\subsection{Novos desafios e possibilidades para o ensino da língua inglesa}

Como sugere Squire et al. (2005, p. 34), jogos sérios nos dão acesso às diversas maneiras de pensar de especialistas (incluindo os conhecimentos, as habilidades, os valores e as disposições) e nos convidam a experienciar o mundo de novas maneiras. Os autores alegam também que os jogos sérios procuram desenvolver fluência dentro de um domínio semiótico, bem como a habilidade de identificar problemas, produzir conceitos baseados em domínios sofisticados, expressar-se por meio da linguagem oral e escrita, produzindo significados por meio de uma variedade de textos e ferramentas. 
Essas percepções também ficaram evidentes nos dados coletados mediante um questionário de avaliação aplicado à equipe envolvida no projeto interdisciplinar. No período investigado, a equipe era formada por sete participantes, a qual avaliou a experiência de participação no projeto como positiva, conforme mostra o Excerto 1. Nesses fragmentos os participantes destacam os conhecimentos ampliados pela sua inserção no projeto de pesquisa, destacando o aperfeiçoamento teórico, tecnológico e linguístico dos participantes envolvidos.

\section{Excerto 1}

"Foi possível ampliar a minha capacidade de criação de atividades em língua inglesa no âmbito digital, além de abrir horizontes para novos conhecimentos na área de programação e informática" (P1).

"As atividades desenvolvidas no projeto proporcionaram conhecimento na plataforma utilizada e uma aproximação com a linguagem de games em ambientes virtuais 3D. Isto influenciou diretamente meu projeto de mestrado, o qual propõe a criação de um gamearte utilizando a mesma plataforma" (P2).

"Dentre as contribuições que a realização das atividades proporcionou está a minha inserção no mundo da pesquisa e, consequentemente, o aperfeiçoamento da habilidade de leitura e síntese de textos" (P3).

"Contribuíram para eu ter fundamentação teórica para o desenvolvimento desse e de outros projetos de pesquisa; para divulgação dos trabalhos realizados e socialização com diferentes grupos e com isso maior aprendizagem; melhoria nas minhas aulas, currículo" (P4).

Além disso, os participantes destacaram os benefícios que essa experiência lhes tem proporcionado. Entre os benefícios citados destacaram-se que o engajamento no projeto "estimulou a busca por novos conhecimentos e softwares para o desenvolvimento de jogos; proporcionou melhoria no letramento digital; instigou o aprofundamento sobre recursos de programação, design, recursos de animação em $3 D$ (animator) $e$ editoração de imagens; gerou a busca por novos conhecimentos teóricos e pedagógicos para o ensino de línguas". Isso demonstra que o envolvimento em projetos dessa natureza qualifica os participantes a assumirem novos papéis e funções no contexto profissional que vão além daquelas esperadas por um aluno em formação inicial, uma vez que poderão em suas futuras atuações profissionais se especializar como programadores, designers, conteudistas, editores, criadores de imagens e 
A produção de jogos sérios interdisciplinares na universidade...

animações em 3D, profissões estas que, gradativamente, ganham destaque no mercado de trabalho.

No caso específico da área de Letras, ao professor na contemporaneidade não basta apenas ter conhecimento linguístico, precisa qualificar-se teórica e pedagogicamente quanto ao uso de tecnologias digitais, ou seja, manusear, avaliar, explorar e criticar recursos tais como redes sociais, podcasts, webquests, jogos online, narrativas digitais, entre outros, que podem ser utilizados em sala de aula. Nossos alunos cada vez mais se inserem em interações virtuais que potencializam as práticas sociais e discursivas virtualizadas que fazem parte do cotidiano dos alunos, bem como se tornam contextos de aprendizagem.

Além desses, outro benefício apontado pelos participantes é sobre a melhor compreensão quanto ao uso de jogos na sala de aula de línguas. A participação nos projetos do nosso grupo de pesquisa, na opinião de $86 \%$ dos participantes, resultou no melhor entendimento teórico sobre o uso de jogos no ensino de línguas, conforme mostram os fragmentos (Excerto 2) coletados pelo questionário avaliativo.

\section{Excerto 2}

"Tentei mesclar minha experiência de jogador com o ensino de língua [....] as leituras e discussões ajudaram a compreender melhor, deixar mais claros alguns pontos e questionamentos novos surgiram"(P1).

"As reuniões e discussões com o grupo foram muito importantes para um melhor entendimento a respeito dos jogos online de ensino" (P3).

"Sim, pois através desse realizou-se a busca teórica e dessa forma tentou-se aplicar a teoria na prática, algo que em alguns momentos foi algo complicado por se tratar em alguns aspectos no problema referente à plataforma e também como conhecimento referente ao desenvolvimento do jogo" (P4).

"Foi possível conectar muita teoria com a elaboração do jogo. Além disso, adotar estratégias de jogos comerciais e adaptá-las para jogos educativos mostrou-se bastante útil para tornar o jogo mais dinâmico e divertido" (P6).

"Apesar de ter entrado recentemente no projeto, já consegui perceber a importância do uso de jogos online no ensino, principalmente no que se refere à aprendizagem de linguas estrangeiras" (P7).

Apesar de não ser a abordagem mais popular de integração de jogos na sala de aula, no nosso caso específico acreditamos que a produção de jogos educativos na universidade poderá fomentar o letramento digital 
dos participantes, bem como possibilitar que os alunos envolvidos desenvolvam competências essenciais aos profissionais deste século para que sejam capazes de identificar novos contextos de uso da linguagem e práticas sociais mediatizadas por meio de tecnologias diversas.

O professor de línguas atualmente precisa ter fluência tecnológica e letramento digital, ou seja, ele precisa entender as idiossincrasias do contexto digital para atuar eficientemente nesse espaço virtualizado. Não basta apenas saber usar, é preciso refletir sobre seu uso, sobre práticas, eventos e situações comunicativas em que os usuários da internet se engajam. Para tal, é preciso formação na universidade que qualifique a prática de multiletramentos desses futuros profissionais com o propósito de atuarem por intermédio de diferentes contextos, eventos, situações comunicativas e práticas discursivas que se realizam virtualmente (REIS, 2010, p. 188-190).

\section{Considerações finais}

Neste artigo discutimos aspectos teóricos e práticos relacionados à experiência de desenvolvimento de jogos educacionais críticos - em desenvolvimento em nosso grupo de pesquisa. Para isso, buscamos identificar o que a teoria em AMJD apresenta sobre como abordar a produção e o uso de jogos na sala de aula.

Com base no estudo teórico apreendemos que os bons jogos possuem princípios de aprendizagem que podem favorecer a aprendizagem. Diante disso, consideramos apropriado no planejamento e no desenvolvimento de jogos a preocupação com a implementação desses princípios.

No desenvolvimento do protótipo, os desafios enfrentados pela equipe fizeram com que os alunos universitários aprendessem a conectar teoria e prática além de permitir a reflexão sobre o uso de jogos digitais na sala de aula. Para atender a esses objetivos, descrevemos no artigo como os aspectos teóricos são visualizados na prática de implementação dos princípios de aprendizagem de Gee (2005) no Jogo I-AI3, especialmente na elaboração das atividades propostas por meio da narrativa planejada.

Ao desenvolver o projeto interdisciplinar com jogos, percebemos nosso avanço com relação a alguns aspectos, principalmente quanto aos elementos que devem estar presentes em uma narrativa de um jogo 
A produção de jogos sérios interdisciplinares na universidade...

educacional, bem como quanto à necessidade de reproduzir situações que explorem potenciais recursos da plataforma de um jogo.

Ao inserir alunos de graduação de diferentes áreas disciplinares nesse processo, percebemos que esse contexto se diferencia das práticas tradicionais de ensino e aprendizagem, as quais exploramos diariamente na escola ou na universidade, o que exige e requer do futuro professor outros conhecimentos que vão além dos linguísticos. Com isso, percebemos também que preparar futuros professores com competências variadas para que consigam ampliar tais conhecimentos em sala de aula, mais especificamente sobre o uso de jogos em sala de aula, é um desafio tanto para a orientadora do projeto quanto para os alunos envolvidos, na medida em que a investigação sobre o uso de jogos digitais no ensino de línguas estrangeiras e a produção de jogos educativos em LI, especificamente no Brasil, ainda é um tema novo nas pesquisas em LA, conforme mostra a análise das publicações em periódicos brasileiros (REIS; BILIÃO, 2014, p. 8-9).

É oportuno salientar ainda que nos cursos de graduação em Letras não há disciplinas que formem ou preparem os alunos para as novas atuações profissionais, tais como conteudistas de cursos online ou desenvolvedores de materiais didáticos digitais, por exemplo, produção de jogos, objetos de ensino e aprendizagem, que envolvam tecnologias digitais em redes para o ensino da linguagem. Na sociedade contemporânea, em que novos papéis e funções são desempenhados por meio de tecnologias digitais, é primordial formar alunos com novos perfis para atuarem e suprirem as necessidades do mercado de trabalho, tendo em vista que o uso de tecnologias se torna um campo primordial e passível de atuação. Nesse sentido, a participação dos alunos do curso de Letras e de outras áreas de conhecimento no projeto promove a prática de novos e multiletramentos, tão essenciais para a atuação profissional na sociedade atual.

A falta de motivação para aprendizagem de línguas no contexto escolar é uma das dificuldades encontradas por muitos professores, principalmente porque a escola atualmente não está preparada para dar conta das necessidades dos nativos digitais, os quais, normalmente, possuem melhor fluência tecnológica que os professores em serviço. Para tanto, é preciso também que a instituição de ensino propicie condições favoráveis para utilizar tais recursos no contexto escolar. No nosso caso específico, muitas vezes ainda não temos as condições adequadas para a 
construção do projeto no nível que desejamos, mas isso não é impedimento para testarmos algumas possibilidades, apesar das limitações encontradas.

Desse modo, concordamos com McGonigal (2012, p. 16-18) que o design de jogos não é apenas um ofício tecnológico, mas uma maneira de no século XXI pensar e liderar conhecimentos variados. Como sugere a autora, o ato de jogar não é apenas um passatempo, mas pode ser considerado uma abordagem para melhorar o trabalho em grupo visando a conquistar mudanças reais.

Por fim, mesmo que você não crie jogos nem nunca jogue, poderá se beneficiar enormemente em aprender como os bons jogos funcionam e como eles podem ser usados para corrigir os problemas do mundo real (McGONIGAL, 2012, p. 12-18). Assim, nossa principal meta com o desenvolvimento de jogos é despertar nos alunos novas reflexões, ações e atitudes em suas práticas diárias como cidadãos do mundo, capacitando-os a comunicarem tais ideias não apenas em suas comunidades locais, mas também no mundo recorrendo à língua inglesa.

\section{Agradecimentos}

Agradecemos aos alunos participantes do projeto, especialmente aos bolsistas Roger Panciera, Mauricio Bilião, Priscila Leonardi Probic/Fapergs (2013); Vitor Menezes e Maicon Anschau - FIT (2013) pela síntese de dados nos relatórios do projeto, bem como na construção de alguns dos desafios elaborados para o jogo, que serviram de base para a escrita deste artigo.

\section{Referências}

BARKHUIZEN, Gary. Social influences on lenguage learning. In: DAVIES, Alan; ELDER, Catherine (Ed.). The handbook of Applied Linguistics. Oxford: Blackwell, 2004. p. 552-575.

CORNILLIE, Frederik; THORNE, Steven. L.; DESMET, Piet. Digital games for language learning: challenges and opportunities. ReCALL, v. 24, p. 243-256, 2012. 
A produção de jogos sérios interdisciplinares na universidade...

; CLAREBOUT, Geraldine; DESMET, Piet. Between learning and playing? Exploring learners perceptions of corrective feedback in an immersive game for English pragmatics. ReCALL, v. 24, p. 257-278, 2012.

FAIRCLOUGH, Norman. Semiotic aspects of social transformation and learning. In: ROGERS, Rebecca. (Ed.). A introduction to critical discourse analysis in education. London: Lawrence Erlbaum Associats, Inc, 2004. p. 225-236.

GEE, James P. What video games have to teach us about learning and literacy. New York: Palgrave Macmillian, 2003.

. Good video games and good learning. Phi Kappa Phi Forum, v. 2, n. 85 , p. 33-37, 2005.

GILLEN, Julia; BARTON, David. Digital literacies: a research briefing by the technology Enhanced Learning phase of the Teaching and Learning Research Programme. 2010. Disponível em: <http://www.tlrp.org/docs/DigitalLiteracies.pdf>. Acesso em: 22 febr. 2015.

JOHNSON, Steven. Surpreendente! A televisão e o videogame nos tornam mais inteligentes. Rio de Janeiro: Campus, 2005.

LITTLEWOOD, William. Second language learning. In: DAVIES, Alan; ELDER, Catherine (Ed.). The handbook of Applied Linguistics. Oxford: Blackwell, 2004. p. 501-524.

MCGONIGAL, Jane. Realidade em jogo: por que os games nos tornam melhores e como eles podem mudar o mundo. Rio de Janeiro: Best Seller, 2012.

OXFORD, Rebecca L. Relationships between second language learning strategies and language proficiency in the context of learner autonomy and selfregulation. Revista Canaria de Estudios Ingleses, n. 38, p. 109-126, 1999. 
PERERA, Indika et al. Managed Learning in 3D Multi User Virtual Environments. International Journal of Digital Society $(I J D S)$, v. 1, n. 4, p. 256-264, Dec. 2010.

PETERSON, Mark. Learner interaction in a massively multiplayer online role playing game (MMORPG): a sociocultural discourse analysis.

ReCALL, v. 24, n. 1, p. 361-380, 2012. 24, n. 1, p. 20-39, 2012a.

PRENSKY, Marc. Digital Natives, Digital Immigrants. On the Horizon, MCB University Press, v. 9, n. 5, Oct. 2001. Disponível em: <http://www.marcprensky.com/writing/Prensky - Digital Natives, Digital Immigrants - Part1.pdf>. Acesso em: 18 ago 2012.

RAMA, Paul S. et al. Affordances for second language learning in World of Warcraft. ReCALL, v. 24, n. 1, p. 322-338, 2012.

REIS, Susana Cristina dos. Do discurso à prática: textualização de pesquisas sobre o ensino de inglês mediado por computador. 227 f. Tese (Doutorado em Letras) - Universidade Federal de Santa Maria, Santa Maria, 2010.

REIS, Susana Cristina dos. et al. O jogo I-AI3: um protótipo em desenvolvimento. RENOTE. Revista Novas Tecnologias na Educação, v. 10, p. 1-10, 2012.

; SOUZA, Rosangela S.; GOMES, Adilson F. Ensino e aprendizagem de línguas mediado por computador: conectando teoria e prática em um jogo. Domínios de Lingu@gem, v. 6, p. 137-149, 2012.

; BILIÃ̃O, Maurício. O uso de jogos digitais nas áreas de Educação e Letras em publicações brasileiras: mapeando o estado da arte. Cenários: Revista de Estudos da Linguagem, v. 2, p. 4-17, 2014.

SQUIRE, Kurt et al. From users to designers: building a self-organizing game-based learning Environment. TechTrends: Linking Research \& Practice to Improve Learning, v. 49, n. 5, p. 34-43, 2005. 
A produção de jogos sérios interdisciplinares na universidade...

SYLVÉN, Liss K.; SUNDQVIST, Pia. Gaming as extramural English L2 learning and L2 prociency among young learners. ReCALL, v. 24, n. 1, p. 302-321, 2012.

THORNE, Steven L.; FISCHER, Ingrid; LU, Xiaofei. The semiotic ecology and linguistic complexity of an online game world. ReCALL, v. 24, n. 1, p. 279-301, 2012.

ULICSAK, Mary; WRIGHT, Martha. Games in education: serious games. Bristol: Futurelab, 2010.

VAN ECK, Richard. Digital game-based learning: It's not just the digital natives who are restless, Educause, v. 41, n. 2, Mar./April. 2006.

VYGOTSKY, Lev. S. Pensamento e linguagem. Tradução de Jefferson Luiz Camargo. 4. ed. Rio de Janeiro: Martins Fontes, 2008.

WITTKE, Carina; REIS, Susana Cristina dos. O ensino da língua inglesa por meio de jogos educativos online. In: OLIVEIRA, Andreia; ROSA, Rosane. (Org.). TIC aplicadas à Educação: usos, apropriações e convergências. 1 ed. Santa Maria: Facos, 2013. v. 1, p. 399-420.

ZHENG, Dongping; NEWGARDEN, Kristi; YOUNG, Michael F. Multimodal analysis of language learning in World of Warcraft play: Languaging as Values-realizing. ReCALL, v. 24, n. 1, p. 339-360, 2012.

ZYDA, Michael. From visual simulation to virtual reality to games. Computer, v. 9, n. 38, p. 25-32, 2005.

Submetido em: 26/06/2015

Aceito em: 03/12/2015

Title: Developing interdisciplinary serious games at university: new challenges and possibilities to language teaching 